\title{
A review of common psychedelic drugs
}

\section{S Mayet}

Department of Anaesthesia, Rahima Moosa Mother and Child Hospital, University of the Witwatersrand, South Africa Corresponding author, email: shafs.mayet@gmail.com

\section{Summary}

Psychedelic substances have traditionally been used in medicine and religious rituals. Their use dates back thousands of years with fossil evidence as old as 10000 years. Throughout the 1950s and 1960s psychedelics were used in clinical studies. These drugs then saw widespread use in hippie culture and were viewed as a drug of abuse with no medicinal value. ${ }^{1}$ Currently, psychedelics are being investigated as adjuncts to existing psycho therapeutic approaches including depression and addiction. ${ }^{1}$ This article will look at definitions, classifications, effects and basic pharmacokinetics and pharmacodynamics of these drugs. In this review I will refer to this group of drugs as psychedelics.

\section{Definitions}

The term psychedelics has been under scrutiny in recent years. Initially, psychedelics were termed hallucinogens, however, we now know that they are not the same.'

Hallucinogens: Refers to a chemical and pharmacological group of substances that cause a distortion in sensory perception of something that does not exist and a mental state resembling psychosis. ${ }^{2}$

Entactogens: Refers to a class of psychoactive drugs that produce empathy or sympathy and includes emotional openness, oneness and communion with others. ${ }^{1}$

Psychedelics: Refers to the capacity of a drug to reliably induce states of altered perception, thought and feeling that are not otherwise experienced except in dreams or at times of religious exaltation. ${ }^{1,2}$ It also refers to the mind-altering substances that have an effect on the conscious experience. ${ }^{2}$

Entheogens: Refers to newer terminology and is slowly replacing both psychedelics and hallucinogens. It literally means "generating the divine within" but loosely means "non-addictive artificial and natural substances that induce alterations in consciousness."1 They are a group of substances that induce alterations in perception, mood, consciousness, cognition and behaviour for the purpose of religious or spiritual significance. ${ }^{1}$

\section{Classification of psychedelic drugs}

These drugs are classified by the neurotransmitters they mimic.

\begin{tabular}{|c|c|c|c|c|c|}
\hline Drug class & Cholinergics & Entactogens & Serotonergics & Glutaminergics & $\begin{array}{l}\text { Opioid kappa } \\
\text { receptor agonists }\end{array}$ \\
\hline Examples & $\begin{array}{l}\text { - Muscarine } \\
\text { - Scopolamine }\end{array}$ & $\begin{array}{l}\text { - Mescaline } \\
\text { - Amphetamines } \\
\text { - Myristicin } \\
\text { - Elemicin }\end{array}$ & $\begin{array}{l}\text { - Lysergic Acid Diethylamide } \\
\text { (LSD) } \\
\text { - N,N-Dimethyltryptamine } \\
\text { (DMT) } \\
\text { - Psilocybin }\end{array}$ & $\begin{array}{l}\text { - Phencyclidine } \\
\text { (PCP) } \\
\text { - Ketamine }\end{array}$ & - Slavinorin A \\
\hline $\begin{array}{l}\text { Mechanism } \\
\text { of action }\end{array}$ & $\begin{array}{l}\text { - Acts on acetylcholine } \\
\text { - Acts on muscarine } \\
\text { - Gamma amino } \\
\text { butyric acid (GABA) } \\
\text { agonist }\end{array}$ & $\begin{array}{l}\text { - 5-Hydroxytryptamine } \\
\text { (5-HT) releasing } \\
\text { - Catecholamine }\end{array}$ & - 5-HT2A agonist & $\begin{array}{l}\text { - Dissociatives } \\
\text { - Inhibits } \\
\text { N-methyl-D- } \\
\text { aspartic Acid } \\
\text { (NMDA) }\end{array}$ & $\begin{array}{l}\text { - Acts on opioid } \\
\text { kappa receptors } \\
\text { - Acts on dopamine } \\
2 \text { (D2) receptors }\end{array}$ \\
\hline
\end{tabular}

\section{Cholinergic psychedelic drugs s $^{3,4}$}

Common examples include

\section{Muscarine}

2. Scopolamine

\section{Muscarine $^{3}$}

Muscarine is a toxic alkaloid found in Amanita muscaria (fly fungus) and other fungal species like Inocybe. ${ }^{8}$ It acts on muscarinic receptors and is an agonist at GABA and is therefore 
neuro depressant. ${ }^{3}$ Its effects include delirium, salivation, nausea and diarrhoea, hypotension and shock. ${ }^{3}$ The antidote is atropine. ${ }^{3}$

\section{Scopolamine ${ }^{3,4}$}

Also known as deadly nightshade. It is a belladona alkaloid and a muscarinic antagonist that is mainly anticholinergic and has psychological effects. Clinically it is used to treat motion sickness, relax smooth muscles and gastric cramping, mild with increasing doses, restlessness, confusion, stupor, respiratory depression and coma.

\begin{tabular}{ll} 
Effects $^{3,4}$ & \\
\hline Parasympathetic effects & Pupillary dilation \\
Dry mouth & Smooth muscle relaxation \\
Decreased sweating & Dry skin \\
Blurred vision & \\
Central nervous system effects & Decreased REM sleep \\
Drowsiness & Mental confusion \\
Mild euphoria & Decreased focus and attention \\
\hline
\end{tabular}

Entactogens (5-HT releasing agents) $)^{1,5}$

These drugs are catecholamine-like in nature. Examples include the phenethylamine mescaline, amphetamines, myristicin and elemicin. ${ }^{5}$

\section{Phenethylamine}

A group of organic compounds which act as a stimulant on the central nervous system. They are used as a dietary supplement and to support mood. They are found occurring in nature, produced by certain fungi and bacteria and can be found in chocolates. $^{5}$ This group of drugs resemble noradrenaline and dopamine and probably exhibit their effect by being a HT2A agonist. These drugs are usually ingested orally and metabolised in the small intestine by monoamine oxidase $B$ (MAO-B) to aldehyde dehydrogenase and then to phenylacetic acid..$^{6,7}$

\section{Mescaline $^{8}$}

It is a naturally occurring psychedelic alkaloid of the phenethylamine derivative. Predominantly used in native America during religious ceremonies for its mystical properties. It originates from the peyote cactus (Lophophora williamsii) where the active ingredient is mescaline. ${ }^{8}$

It is a hallucinogen with psychoactive properties and is 4000 times less potent than LSD. The dosage range is between 200-300 mg. The structure of mescaline is similar to serotonin, psilocybin and LSD. ${ }^{8}$

\section{Pharmacokinetics}

Mescaline is ingested orally and rapidly absorbed within 30 minutes via the gastrointestinal tract. Its psychedelic effects are reached within two hours of ingestion and lasts up to eight hours. The plasma half-life is approximately six hours. ${ }^{8}$ Mescaline has poor lipid solubility and therefore has poor passage across the blood-brain barrier. ${ }^{8}$

It is mainly metabolised via the liver and up to $87 \%$ is excreted in the urine within 24 hours. $^{8}$

\section{Physiological effects ${ }^{8}$}

Sympathomimetic activity and mimics noradrenaline and adrenaline mainly, and effects include:

- Nausea, vomiting, dizziness, sweating and chills

- Dilated pupils

- Dry mouth

- Anxiety

- Ataxia, hyperreflexia

- Sedation

\section{Neuropsychiatric effects ${ }^{8}$}

- Depersonalisation

- Complex hallucinations

- Altered perception especially for colour, sound and shape and for space and time

- Intact sensorium

\section{Synthetic amphetamines}

Methylene-dioxy-methamphetamine (MDMA) is one of the commonest. It is used recreationally. ${ }^{9}$ Structurally, MDMA is similar to mescaline and resembles adrenaline and noradrenaline. Its biological actions are similar to adrenaline, dopamine and serotonin where it does not act directly on serotonin but rather blocks and binds to serotonin transporter involved in its uptake. It is synthetically derived and is also known as a "designer drug".9

Other street names include "ecstacy", "XTC", "ADAM", "speed", "Molly".12 The route of administration includes oral, intravenous, snorting or adding to drinks (spiking). The dosage varies from 50-150 mg. ${ }^{9}$

Uses $^{9}$

Mainly used recreationally at raves and clubs, MDMA is viewed as a fairly safe drug as it is perceived to postpone fatigue and cause euphoria.

There is renewed interest for MDMA usage in psychotherapy and trials are currently underway for its use in post-traumatic stress disorder and for anxiety in the terminally ill and autistic population.

\section{Pharmacokinetics $^{9}$}

MDMA is readily absorbed from the gastrointestinal tract within two hours of oral ingestion. $80 \%$ is metabolised via the liver via O-demethylation and $\mathrm{N}$-dealkylation. $20 \%$ is excreted unchanged in the urine. Slow elimination from the body with persistence of effects after two days occurs. 
Effects $^{9}$

\section{Short-term}

Acute adverse effects are usually the result of high or multiple doses. The most serious short-term physical health risks of MDMA are hyperthermia and dehydration. Cases of life-threatening or fatal hyponatremia have been reported due to excessive water intake. Other side effects include bruxism, insomnia, sweating, diarrhoea, hypertension and tachycardia. Visual and auditory hallucinations rarely occur.

\section{Long term ${ }^{9}$}

Psychological effects include depression, impulsiveness, memory impairment and paranoia. Long-term exposure to MDMA in humans has been shown to produce marked neurodegeneration in striatal, hippocampal, prefrontal, and occipital serotonergic axon terminals.

\section{Myristicin and elemicin ${ }^{10}$}

Derivatives include nutmeg and anise. Effects include euphoria, visual hallucinations, psychosis, paranoia of death, tremors, nausea and vomiting. ${ }^{10}$

\section{Serotonergic drugs - 5-HT2A agonists ${ }^{2}$}

The exact mechanism of action of this sub class of psychedelic drugs is not known but they have different affinities for various 5-HT receptors. Examples of drugs in this class include:

a. Lysergic acid diethylamide (LSD)

b. Psilocybin

c. N,N-Dimethyltryptamine (DMT) - ayahuasca

d. Harmine

e. Ololiuqui

A discussion on LSD, psilocybin and DMT will follow.

\section{$L S D^{2,11}$}

Also known as the prototype hallucinogen, LSD was first synthesised in 1938 by Albert Hoffmann from lysergic acid which is derived from the ergot fungus. ${ }^{2}$ The 1960 s saw the emergence of the psychedelic movement where LSD was used recreationally and spiritually.

\section{Pharmacokinetics}

LSD is ingested orally and completely absorbed by the gastrointestinal system. 100-250 ug LSD orally produces neuropsychiatric effects and sympathomimetic effects for 30-45 minutes and peaks at 1.5-2 hours. ${ }^{11}$ The effects last 6-12 hours depending on dosage, tolerance, body weight and age. Distribution of the drug is mainly via the gastrointestinal tract. ${ }^{11}$

Information on LSD metabolism is limited and mostly studied in rats and guinea pigs. It has been postulated that it is metabolised via nicotinamide adenine dinucleotide (NADH)-dependant microsomal liver enzymes to inactive 2-oxy-LSD and 2-oxy-3-
O-H-LSD. LSD is eliminated via the urine. ${ }^{11}$ LSD is still detectable four days post ingestion. ${ }^{11}$

\section{Pharmacodynamics ${ }^{11}$}

LSD is an atypical psychedelic as it has both serotonergic and dopaminergic activity. It has mixed affinity for 5-HT1 and 5-HT2 receptors but mainly 5-HT2 where it increases glutamate levels. LSD interacts agonistically and antagonistically at the D1 and D2 receptors.

\section{Effects $^{2,11}$}

Physical effects include insomnia, decreased appetite, weakness, nausea, temperature changes, tachycardia and hyperreflexia. Psychiatric adverse effects include a "bad trip" that involves anxiety, panic, mood swings, flashbacks with hallucinations and feelings of losing control. Overdoses are not directly linked to death, but suicides have been reported.

With repeated administration, there is a decrease in responsiveness to LSD especially in psychological and autonomic side effects. No long-lasting effects on the brain have been reported. ${ }^{2,11}$

In a nutshell, the mechanism of action of LSD is still not fully understood. It is however well tolerated physiologically and has no permanent effects on the brain.

\section{Psilocybin ${ }^{2,12}$}

Initially psilocybin was part of the hallucinogens, but hallucinations are not always present therefore they are classified as psychedelic drugs. ${ }^{12}$ They belong to the tryptamine alkaloids and are structural analogues to serotonin. Tryptamines are natural compounds or designer drugs that originate from the decarboxylation of tryptophan.

Psilocybin is found in mushroom species, especially the psilocybe mushrooms and is also known as "magic mushrooms" or "shrooms".12 They are ingested dried or fresh and found mainly in north-west or south of USA.

\section{Pharmacokinetics}

Psilocybin is the prodrug to psilocin which is the active metabolite. ${ }^{12}$ Via dephosphorylation, the phosphate group of psilocybin is removed creating psilocin. ${ }^{12}$ Once dephosphorylated (via alkaline phosphatase), psilocin becomes lipid soluble and crosses the blood-brain barrier more easily. ${ }^{12}$ Both psilocybin and psilocin are detected in the blood 20-40 minutes after ingestion reaching maximum levels at $80-105$ minutes..$^{12} 80 \%$ is excreted in the urine as psilocin-o-glucuronide and $3-10 \%$ as a glucuronide. ${ }^{12}$

\section{Pharmacodynamics ${ }^{12}$}

Psilocybin has low binding affinity for 5-HT2A compared to the more active psilocin. Psilocin can be blocked by the $5-\mathrm{HT} 2 \mathrm{~A}$ antagonist, ketanserin. 
Effects $^{12}$

Highly variable and depends on the cultivar consumed and dosage ingested. Physiological effects include pupil dilation, changes in heart rate and blood pressure, tremors, hyperreflexia and nausea. Psychological effects include panic and a "bad trip" (but not as pronounced as with LSD), flashbacks, psychosis, euphoria and depression.

\section{DMT (N,N-Dimethyltryptamine $)^{2,9}$}

DMT has been used for possibly thousands of years by Amazonian tribes that activate DMT innately in rainforest plants by brewing it in tea, called ayahuasca. DMT is a hallucinogenic tryptamine analogue that occurs naturally in many plants and animals.

\section{Effects $^{2,9}$}

Mainly psychological with intense visual and auditory hallucinations and an altered sense of space, body, and time.

\section{Glutaminergic drugs - dissociatives}

Dissociatives are structurally unrelated to the other psychedelic drugs. They do not involve 5-HT, acetylcholine or dopamine. ${ }^{13}$ They are non-competitive agonists of the $\mathrm{N}$-methyl-D-aspartate (NMDA) receptor which is a subtype of the major excitatory neurotransmitter in the brain, glutamic acid.

There are four main groups of dissociatives: ${ }^{13}$

1. Arylcyclohexamines - phencyclidine (PCP), ketamine

2. Dizocilpine - MK 801

3. Dextromethorphan (DXM) - found in cold and flu preparations

4. Nitrous oxide

The focus for this article will be arylcyclohexamines, PCP and ketamine.

\section{Phencyclidine}

PCP was originally developed as an intravenous anaesthetic agent but was withdrawn due to its side effect profile which includes delirium, seizures and delayed emergence. ${ }^{13}$ PCP is a non-competitive agonist at the NMDA receptor. ${ }^{13}$ It is also known as "angel dust".

\section{Pharmacokinetics}

PCP can be snorted, smoked, taken orally or injected intravenously. ${ }^{13}$ It is also added to cigarettes and cannabis so it can be smoked. $90 \%$ of PCP is metabolised by oxidative hydroxylation in the liver during the first pass. Metabolites are glucuronidated and excreted in the urine. ${ }^{13}$ PCP is excreted $9 \%$ in its unchanged form. The onset of PCP is $15-60$ minutes. ${ }^{13}$ It has a half-life between $7-46$ hours. $^{13}$

\section{Effects}

Low doses illicit feelings of detachment from body and surroundings, social withdrawal, disorientation, agitation, confusion and psychosis. ${ }^{13}$ Higher doses cause catatonia, semi coma and full coma and seizures. ${ }^{13}$ PCP has addiction potential with long term use and can cause intoxication which requires supportive management, antipsychotics and the use of benzodiazepines. ${ }^{13}$

\section{Ketamine}

Ketamine is an anaesthetic agent currently in use. Ketamine was discovered in 1962, first tested in humans in 1964, and approved for use in the United States in 1970. It was extensively used for surgical anaesthesia in the Vietnam War due to its safety profile. Multiple routes of administration exist which include oral, intravenous (IV), intramuscular (IM), per rectum and intranasal. ${ }^{14}$

Uses $^{14}$

Ketamine has varied uses which include as an anaesthetic agent, for sedation and pain relief. Newer research is focused on nonanaesthetic uses like depression. ${ }^{14}$ Recently the $\mathrm{S}-(+)$ ketamine has regenerated interest in clinical use due to a better side effect profile.

\section{Mechanism of action ${ }^{13,14}$}

Ketamine produces dissociative anaesthesia. Ketamine blocks the NMDA receptor calcium channel and reduces the presynaptic release of glutamate. Ketamine may also interact with mu and kappa opioid receptors.

\section{Pharmacokinetics ${ }^{13,14}$}

Onset is $30 \mathrm{sec}$ (IV); 3-4 $\mathrm{min}$ (IM). Duration is $5-10 \mathrm{~min}$ (IV); 12-25 min (IM); dissociative state may last more than 20 minutes. Metabolism via liver and metabolites include norketamine and dehydronorketamine. Excretion is via urine (91\%) and faeces (3\%).

\section{Effects of ketamine ${ }^{14}$}

\begin{tabular}{|lll}
\hline System & Effects due to use & $\begin{array}{l}\text { Effects due to } \\
\text { intoxication }\end{array}$ \\
\hline Cardiovascular & $\begin{array}{l}\text { Hypertension, tachycardia, } \\
\text { palpitations, arrhythmias, } \\
\text { chest pain }\end{array}$ & $\begin{array}{l}\text { Hypotension, } \\
\text { bradycardia, } \\
\text { myocardial } \\
\text { infarction }\end{array}$ \\
\hline Neurological & $\begin{array}{l}\text { Paranoia, dysphoria, } \\
\text { anxiety, confusion, } \\
\text { slurred speech, dizziness, } \\
\text { ataxia, dysarthria, } \\
\text { muscular rigidity, } \\
\text { acute dystonic reactions }\end{array}$ & $\begin{array}{l}\text { Seizure, stupor, } \\
\text { coma }\end{array}$ \\
\hline Respiratory & $\begin{array}{l}\text { Respiratory } \\
\text { depression, apnoea }\end{array}$ \\
\hline Abdominal & Pain & \\
\hline General & $\begin{array}{l}\text { Sedation, } \\
\text { decreased level of } \\
\text { consciousness }\end{array}$ \\
\hline
\end{tabular}


Overdose may lead to panic attacks and aggressive behaviour, rarely seizures, increased intracranial pressure and cardiac arrest.

\section{Opioid kappa receptor agonist}

\section{Salvinorin $A^{15}$}

Historically, Salvinorin A was used by the Mazatec Shamans. ${ }^{15}$ The main psychotropic component in the Mexican plant Salvia Divinorum is salvinorin A. It is a dissociative hallucinogen with potent and selective agonism of kappa opioid receptors in the brain. ${ }^{15}$ It works on the opioid kappa receptor (KOR) as an agonist and on the D2 receptor as a partial agonist. ${ }^{15}$ Its effects last 1-2 hours and include mild sympathetic activity, mood changes and a feeling of introspection, dysphoria, psychosis, anhedonia and depression. ${ }^{15}$

\section{Psychedelic drugs: a new frontier? ${ }^{16}$}

Psychedelic drugs have been viewed as drugs of abuse, however, recently, the psychedelics are being investigated for newer and safer uses. Possible future roles may include relooking at the psychedelics in addiction medicine, treatment of cluster headaches, depression and anxiety. However, at this point in time, psychedelics are still a drug of abuse. New, emerging research might look at safer, more beneficial uses for these drugs.

\section{Conflict of interest}

The author declares no conflict of interest.

\section{Funding source}

None.

\section{ORCID}

S Mayet (iD https://orcid.org/0000-0001-8101-4436

\section{References}

1. Nichols DE, Barker EL. Psychedelics. Pharmocol Rev. 2016:68:264-355. https://doi. org/10.1124/pr.115.011478.

2. Delgado J, Traub Sj, Grayzel J. Intoxication from LSD and other common Hallucinogens. UpToDate. 2020 January. Available from: https://www.uptodate. com/contents/intoxication-from-Isd-and-other-common-hallucinogens.

3. Kosentka P, Sprague SL, Ryberg M, et al. Evolution of the toxins muscarine and psilocybin in a family of mushroom-forming fungi. PLOS ONE. 2013;8(5):e64646. https://doi.org/10.1371/journal.pone.0064646.

4. Tulane University. Cholinergic pharmacology (agonists and antagonists). 2016. Available from: http://tmedweb.tulane.edu/pharmwiki/doku.php/cholinergic pharm. Accessed 16 July 2020.

5. Vollenweider FX. Brain mechanisms of hallucinogens and entactogens. Dialogues Clin Neurosci. 2001;3:265-79.

6. McGregor I. Methylenedioxyamphetamine (MDMA). In: McGregor IS, Thompson MR, Callaghan PD, editors. Encyclopedia of psychopharmacology. 1st ed. Berlin/ Heidelberg: Springer; 2010. p. 758-762.

7. Pei Y, Asif-Malik A, Canales JJ. Trace amines and trace amines associated receptor 1: pharmacology, neurochemistry and clinical implications. Front Neurosci. 2016:10:1-12 https://doi.org/10.3389/fnins.2016.00148.

8. Rostock D. Pharmacological constituents of mescaline and salvinorin: a preliminary analysis. University of Idaho. Spring 2003.Available from: https:// webpages.uidaho.edu/psyc490/The\%20Pharmacological\%20Constituents\%20 of\%20Mescaline1.ppt.

9. Kalant H. The pharmacology and toxicology of "ecstasy" (MDMA) and related drugs. CMAJ. 2001;165:917-28.

10. National Library of Medicine (US), National Center for Biotechnology Information; 2004-. PubChem Compound Summary for CID 4276, Myristicin [cited 2020 Sept 23]. Available from: https://pubchem.ncbi.nlm.nih.gov/ compound/Myristicin.

11. Passie T, Halpern JH, Stichtenoth DO, Emrich HM, Hintzen A. The pharmacology of lysergic acid diethylamide: a review. CNS Neurosci Ther. 2008;14:295-314. https://doi.org/10.1111/j.1755-5949.2008.00059.x.

12. Bauer B. The pharmacology of psilocin and psilocybin. Psychedelic Sciences Review. 2019 March. Available from: https://psychedelicreview.com/ the-pharmacology-of-psilocybin-and-psilocin/.

13. Domino EF, Miller SC. The pharmacology of dissociatives. In: Ries R, Fiellin D, Miller SC, editors. The ASAM principles of addiction medicine. 5th ed. America: Lippincott, Williams and Wilkins; 2015. Available from: https://doctorlib.info/ medical/principles-addiction-medicine/15.html.

14. Orhurhu VJ, Claus LE, Vashisht R, Cohen S. Ketamine toxicity. StatPearls (Internet) 2020. Available from: https://www.ncbi.nlm.nih.gov/books/NBK541087.

15. Orton E, Liu R. Salvinorin A: a mini review of physical and chemical properties affecting its translation from research to clinical applications in humans. Trans Perioper Pain Med. 2014;1(1):9-11. https://doi.org/10.31480/2330-4871/004

16. Coilparampil $\mathrm{S}$. The psychedelic renaissance: emerging data on the use of psychedelic drugs in addiction, end of life anxiety and PTSD. Aust N Z J Psychiatry. 2014;49:9-11. 